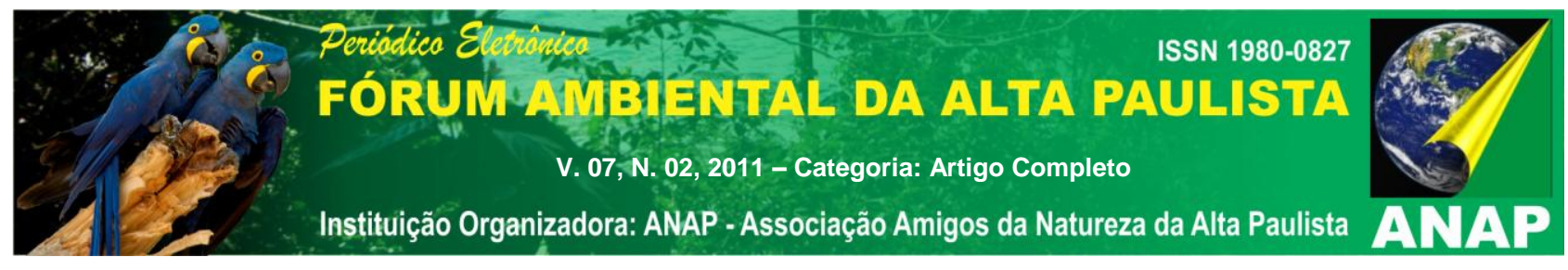

\title{
MAPEAMENTO AMBIENTAL PARTICIPATIVO NO PLANEJAMENTO AMBIENTAL DA BACIA HIDROGRÁFICA DO CÓRREGO EMBIRÍ - UGRHI PONTAL DO PARANAPANEMA - SÃO PAULO
}

\author{
Franciane Mendonça dos Santos ${ }^{1}$ \\ Antonio Cezar Leal ${ }^{2}$ \\ Salvador Carpi $\mathrm{Jr}^{3}$
}

Resumo: Esta pesquisa tem como objetivo subsidiar as atividades de planejamento ambiental da bacia hidrográfica do Córrego do Embirí, localizado na bacia do manancial Rio Santo Anastácio, na UGRHI Pontal do Paranapanema - São Paulo, aplicando-se a metodologia de mapeamento de riscos ambientais e planejamento participativo. A principal atividade no contexto desse método é a reunião pública de mapeamento de riscos ambientais, fornecedora da maior parte das informações e considerada a etapa fundamental para a mobilização social visando à gestão participativa, o planejamento e educação ambiental. Nas reuniões públicas e no trabalho de campo procura-se a integração entre o conhecimento técnicocientífico e o conhecimento empírico e a percepção da população da bacia em relação aos riscos ambientais, fornecendo subsídios para o planejamento ambiental da área, mediante a identificação de problemas específicos, elaboração de propostas e recomendações, integrando a pesquisa com as necessidades da administração pública. Os resultados são sistematizados e apresentados à comunidade para seu conhecimento e validação. Nesse contexto, os resultados obtidos podem colaborar na produção e difusão de conhecimentos, produtos e serviços para o gerenciamento de recursos hídricos, formação e capacitação de recursos humanos, implementação de políticas territoriais e desencadeamento de ações de Educação Ambiental na área de estudo.

Palavras-chave: mapeamento ambiental participativo, planejamento ambiental, Córrego do Embirí.

\section{1 - INTRODUÇÃO}

\footnotetext{
${ }^{1}$ Franciane Mendonça dos Santos, Rua Dona Militânia, 145 - Presidente Prudente - Sp. Email: fran.mendonca@hotmail.com ${ }^{2}$ Antonio Cezar Leal, Rua Roberto Simonsen,305, Jardim das Rosas - Presidente Prudente, SP . Email: cezar@fct.unesp.br

${ }^{3}$ Salvador Carpi Jr, R. Dr João Pandiá Calógeras, 51, Cidade Universitária - Campinas-SP . Email: salvador@ige.unicamp.br
} 


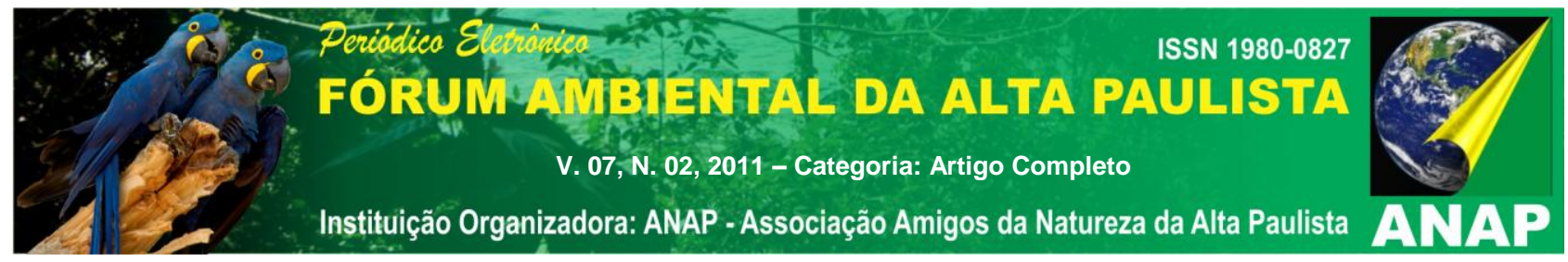

A água é um recurso finito, e essencial como insumo básico para atividades de diversos setores, entretanto, as diferentes intervenções antrópicas no meio ambiente, acabam por prejudicar o equilíbrio da natureza, e podem comprometer sua qualidade, e conseqüentemente a quantidade do recurso para as futuras gerações. Deste modo, é necessário controlar os diversos fatores que influenciam nesta degradação ambiental.

Segundo Mota (1995) o controle feito tomando como base a bacia hidrográfica parece ser o mais racional, pois a qualidade da água de determinado recurso hídrico resulta das atividades desenvolvidas na sua bacia contribuinte. A bacia hidrográfica constitui um sistema natural bem delimitado no espaço, composto por um conjunto de terras topograficamente drenadas por um curso d'água e seus afluentes, onde as interações, pelo menos físicas, são integradas e, assim mais facilmente interpretadas, o que segundo Santos (2004) justifica a sua utilização como unidade de planejamento.

Deste modo a água apresenta-se como o recurso mais importante de uma bacia hidrográfica, estando sua qualidade diretamente ligada com as atividades desenvolvidas na bacia.

Para se atender os padrões e normas impostos pela legislação é necessário um planejamento ambiental minucioso que aborde todos os aspectos da bacia hidrográfica, levando-se em consideração a qualidade e uso que é dado para o recurso hídrico. Segundo Silva et al (2011) planejar o meio ambiente e o território constitui um exercício acadêmico e intelectual direcionado a pensar de forma racional a ocupação e o uso das diferentes partes da superfície do planeta Terra, tendo em conta um instrumental cognitivo e um arcabouço de métodos, técnicas e procedimentos.

Portanto o planejamento ambiental dos recursos hídricos é considerado com um dos mecanismos e instrumentos fundamentais para amenização não apenas dos problemas enfrentados pelos recursos hídricos em termos de deterioração enquanto recurso natural como também para atingir a gestão adequada que garanta o uso múltiplo da água.

\section{2 - FUNDAMENTAÇÃO TEÓRICO-METODOLÓGICA DA PESQUISA}

O planejamento ambiental segundo Santos (2004, p.28) fundamenta-se na interação e integração dos sistemas que compõe o ambiente e tem desta forma a função 


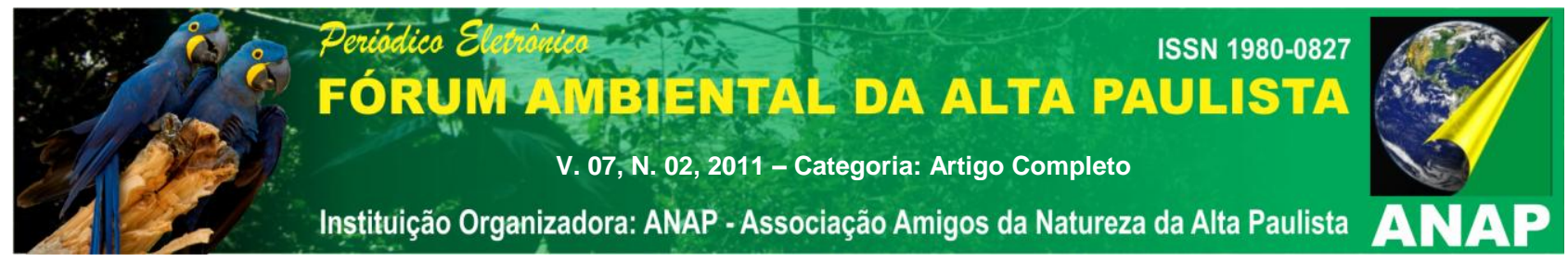

de estabelecer as relações entre o meio ambiente e os processos da sociedade sejam eles econômicos ou culturais. Ainda de acordo com a autora o planejamento ambiental tem como estratégia estabelecer ações dentro de contextos e não isoladamente. $O$ resultado, portanto, é o melhor aproveitamento do espaço físico e dos recursos naturais, economia de energia, alocação e priorização de recursos para as necessidades mais prementes e previsão de situações. Assim para Mateo Rodriguez, 1984 apud Leal (1995, p. 26) o Planejamento Ambiental constitui uma ferramenta efetiva para a conquista da sustentabilidade e um dos instrumentos principais da política ambiental.

Uma das metodologias que podem ser aplicadas ao planejamento ambiental é o Mapeamento participativo visando à identificação dos riscos ambientais pode ser considerado um método de pesquisa que encontra-se inserido no contexto mais amplo caracterizado por diversas formas de mapeamento participativo.

Para Herlihy \& Knapp, apud Acselrad \& Coli (2008), o mapeamento participativo é aquele que reconhece o conhecimento espacial e ambiental de populações locais e insere em modelos mais convencionais de conhecimento, sendo que "diversas iniciativas de mapeamento que se propõe a incluir populações locais nos processos de produção de mapas disseminaram-se mundialmente desde os anos 90"

No Brasil, os autores identificaram 118 experiências de mapeamento participativo segundo auto classificação de seus promotores, com projetos desenvolvidos a partir do início dos anos 90, apresentando uma proliferação particular nos anos 2005 e 2007.

Entretanto, o levantamento indica apenas uma única experiência dessa natureza em gerenciamento de bacias hidrográficas, muito pouco dentro do contexto total, mesmo considerando-se as demais pesquisas e atividades similares não incluídas nessa classificação, mas que também de alguma forma poderiam ser consideradas como "mapeamento participativo".

Uma das formas de mapeamento ambiental participativo com amplas possibilidades de aplicação é aquela que leva em conta percepção ou conhecimento da população afetada pelos riscos ambientais. Carpi Jr \& Dagnino (2007) ressaltam que o respeito pela variedade de formas de percepção dos riscos, acompanhado pela vivência e pelo olhar acostumado com os ritmos e as sutilezas das modificações ambientais, permite a observação de coisas que o especialista, o acadêmico ou o profissional podem 


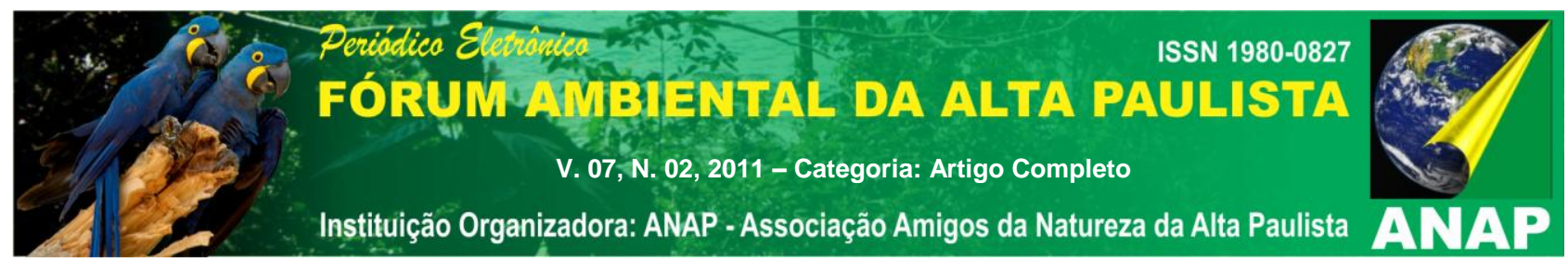

não perceber. Como exemplo, a percepção permite captar os desvios nas médias pluviométricas mensais, permite entender por que determinada área é mais vulnerável aos deslizamentos do que outra de feição geomorfológica semelhante, permitindo o questionamento sobre a qualidade das águas em rios nos quais, esporadicamente, são lançadas cargas incomuns de poluentes.

Segundo Maljazova \& Cjalov (2004), apesar da ampla difusão do termo "risco" na vida atual e do largo uso na Ciência, até o momento não existe uma definição universal do conceito, embora considerem que no seu sentido e compreensão contemporânea pode-se interpretar como a probabilidade de ameaça. O risco seria função da exposição do objeto (a população, a economia) a um impacto natural perigoso, à sensibilidade ou vulnerabilidade desse objeto a esses impactos, e à defesa que pode-se exercer em relação aos mesmos. Assim, o risco somente pode surgir onde a população e a economia se expõem ao perigo, e é avaliado como a probabilidade de ocorrência de tais acontecimentos acompanhados de suas consequências não desejáveis.

Nas experiências e pesquisas sobre o tema, a preferência tem sido dada ao termo risco ambiental, pois considera-se que as situações de risco não estão desligadas do que ocorre em seu entorno - o ambiente, em seu sentido amplo - seja o ambiente natural, seja o construído pelo homem (social e tecnológico). Assim, o risco ambiental torna-se um termo sintético que abriga os demais, sem que os demais sejam esquecidos ou menosprezados. De acordo com a conceituação de Veyret \& Meschinet de Richemond (2007, p. 63), os riscos ambientais "resultam da associação entre os riscos naturais e os riscos decorrentes de processos naturais agravados pela atividade humana e pela ocupação do território."

Nas experiências e pesquisas sobre o tema, a preferência tem sido dada ao termo risco ambiental, pois considera-se que as situações de risco não estão desligadas do que ocorre em seu entorno - o ambiente, em seu sentido amplo - seja o ambiente natural, seja o construído pelo homem (social e tecnológico). Assim, o risco ambiental torna-se um termo sintético que abriga os demais, sem que os demais sejam esquecidos ou menosprezados. De acordo com a conceituação de Veyret \& Meschinet de Richemond (2007, p. 63), os riscos ambientais "resultam da associação entre os riscos naturais e os 


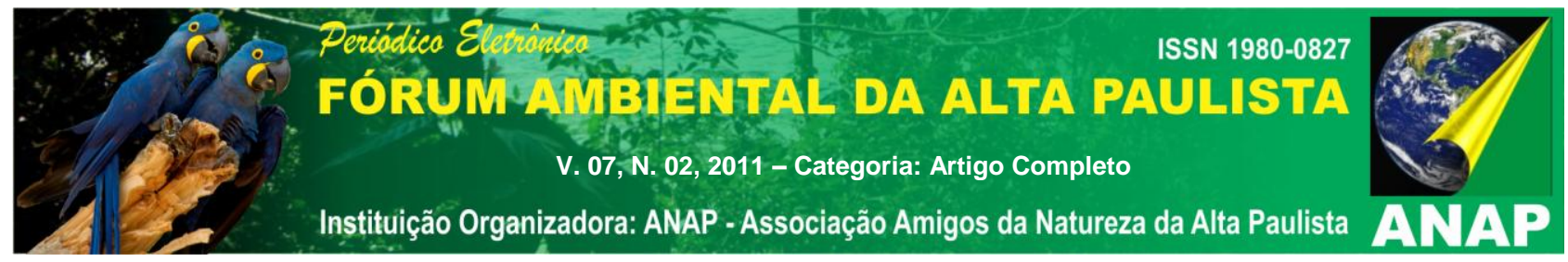

riscos decorrentes de processos naturais agravados pela atividade humana e pela ocupação do território."

Entretanto, Rebelo (2003, p. 252) considera que existe um ponto de confluência: "Independentemente das palavras utilizadas, está, na prática, aceite, por quase todos os que se dedicam a este tipo de estudos, que o risco é, então, o somatório de algo que nada tem a ver com a vontade do homem (aleatório, acaso, casualidade ou perigosidade), com algo que resulta da presença direta ou indireta do homem, ou seja, a vulnerabilidade."

Sanchez (2006) afirma que uma das questões mais relevantes dentro da avaliação de impacto ambiental é a maneira como diferentes pessoas encaram e se comportam diante das situações de risco, sabendo-se que há pessoas mais propensas a aceitar riscos, em qualquer área.

Para Carpi Jr (2001) os impactos ou alterações do ambiente podem se configurar como formas de risco ambiental, que ao ser percebido pelo homem, pode se transformar em ponto de partida para as ações que visem a melhoria da qualidade de vida, juntando esforços dos diversos setores da sociedade.

Entre as possibilidades de combinação entre informações oriundas da percepção da população e demais fontes, com sua aplicação no planejamento e educação ambiental em microbacias hidrográficas, em Leal (1995) para a identificação de unidades ambientais em microbacia do município de Campinas, São Paulo, considerou o mapeamento de unidades físicas, unidades de uso e ocupação do solo, e a percepção e interpretação da realidade local baseada na experiência cotidiana dos moradores e trabalhadores na área. Tal aspecto propiciou a elaboração de um plano motivador, com o objetivo de obter um instrumento de trabalho visando motivar alunos, professores e comunidade local a participar da elaboração de um planejamento ambiental para a área, ou seja, um plano coletivo de desenvolvimento sustentável. O autor acrescenta as condições favoráveis desse tipo de trabalho em microbacias, cuja pequena extensão facilita as atividades de educação e planejamento ambiental para a comunidade civil e escolar.

Sevá Filho (1997), no trabalho efetuado na Região de Campinas, propõe que a forma de abordar o mapeamento de riscos, e a dinâmica das atividades de mapeamento 


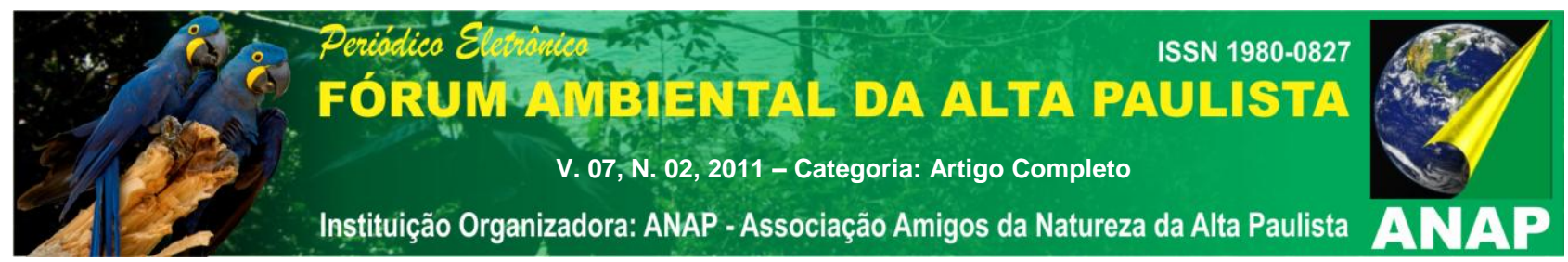

sejam baseadas numa formal alternativa de relação pedagógica, no qual os participantes " aprendem muito mais uns com os outros, e também, consigo próprios, na medida em que sejam estimulados a sistematizar o seu próprio conhecimento adquirido na experiência da vida, como cidadão, como trabalhador, como participante de movimentos associativos, sindicais, ou, simplesmente como morador e usuário da cidade e da região". A relevância de um mapeamento de riscos ambientais foi estabelecida em função de "elaborar um produto de aplicação didática para usar na formação de outras lideranças, e na educação popular. Algo em que os cidadãos se apóiem para o entendimento da própria região e de alguns dos seus próprios problemas". Essa perspectiva fundamentou a aplicação do mapeamento ambiental participativo na bacia do Córrego do Embirí.

\section{3 - CARACTERIZAÇÃO DA ÁREA DE ESTUDO}

A bacia hidrográfica do Córrego do Embiri localiza-se na bacia do manancial Rio Santo Anastácio e abrange terras dos municípios de Regente Feijó e Presidente Prudente.

Esses municípios têm áreas na UGRHI 22, que agrega os tributários da margem direita do curso inferior do rio Paranapanema e alguns afluentes pela margem esquerda do rio Paraná, especialmente o Rio Santo Anastácio, localizando-se na porção extremo oeste do Estado de São Paulo. Os principais rios desta UGRHI são os rios Paranapanema, Paraná, Santo Anastácio e Pirapozinho (CTPI, 1999).

Regente Feijó, São Paulo apresenta as seguintes coordenadas geográficas; 22ํㅡㄴ $13^{\prime}$ de latitude Sul e $31^{\circ} 18^{\prime}$ de longitude Oeste, a altitude da cidade é de 479 metros e possui uma área de $265 \mathrm{~km}^{2}$. O município limita-se com os municípios de Indiana, Martinópolis, Taciba, Anhumas e Presidente Prudente, sendo está última a principal cidade da região.

De acordo com Udenal (1999) a topografia do município acha-se mais elevada na região central, e o sítio urbano encontra-se no divisor de águas. Nas vertentes estão as nascentes dos cursos d'água que seguem três diferentes direções. Em direção ao sudeste o rio Laranja Doce, a sudoeste o rio Santo Anastácio e noroeste, o ribeirão Mandaguari. 


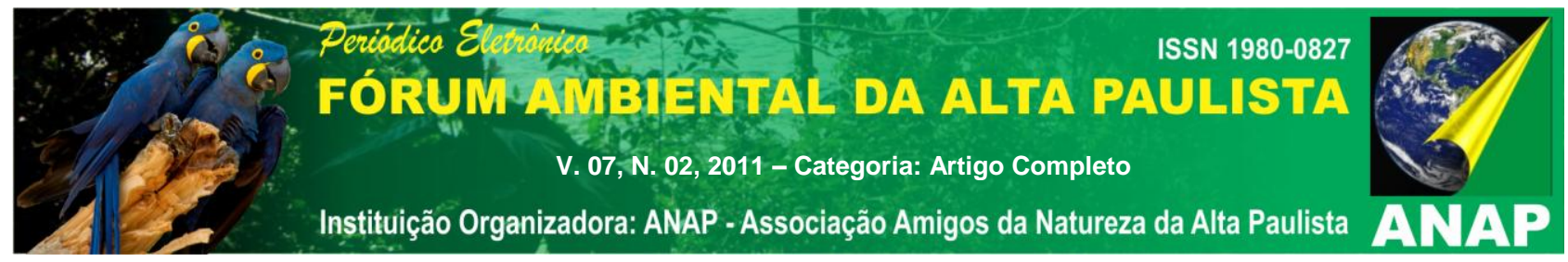

Ainda de acordo com a autora a rede hidrográfica do município, é constituída principalmente pelos rios Laranja Doce, Santo Anastácio e Ribeirão do Mandaguari, que são afluentes dos rios Paranapanema e rio do Peixe, respectivamente. Os cursos d'agua correm sobre o arenito Bauru e estão entalhados em terrenos pouco resistentes, como os sedimentos Cenozóicos.

A captação de água para o abastecimento urbano em Regente Feijó é feita através de poços profundos, pois os rios com volume d'agua viável para a captação estão bastante distanciados (UDENAL, 1999).

Presidente Prudente possui sua fundação em 14 de setembro de 1917, pelo Coronel Francisco de Paula Goulart. Localiza-se a $570 \mathrm{~km}$ a oeste da cidade de São Paulo, constitui sede administrativa e importante pólo da Mesorregião de Presidente Prudente formada por 54 municípios e três micro regiões: Adamantina, Dracena e Presidente Prudente. Possui uma área de $563,62 \mathrm{~km}^{2}$ e está a aproximadamente 475 metros acima do nível do mar. O município de Presidente Prudente está localizado no espigão divisor das bacias do Rio do Peixe e Rio Paranapanema. É cortado pelo paralelo $22^{\circ} 07^{\prime} 57^{\prime \prime} S$ e pelo meridiano $51^{\circ} 22^{\prime} 57^{\prime \prime}$ Wgr.

A topografia do município apresenta-se levemente ondulada com sucessão contínua de colinas, na grande maioria com divisores constituídos por cursos d'água. $\mathrm{O}$ solo é classificado como arenito Bauru, com características agrícolas, o que o torna apto a diversas culturas.

O município utiliza-se de mananciais superficiais e subterrâneos. Segundo Martin (1990), na década de 1990, era abastecido por cerca de 25 poços, com profundidade média de 200 metros, e pelo Rio Santo Anastácio, correspondente a 75\% do abastecimento urbano, e pelo Balneário da Amizade. No entanto, no final desta década entra em operação o sistema Peixe, que responde atualmente por cerca de $70 \%$ da água que abastece a cidade, em razão dos problemas que atingem os demais mananciais superficiais e pela desativação da maioria dos poços.

O rio Santo Anastácio possui grande relevância para a região, em razão dos movimentos sociais e ações institucionais ocorridos e em execução para sua recuperação e proteção, especialmente considerando seu potencial de abastecimento público de Presidente Prudente e a mudança da lógica de utilização, degradação e abandono de 


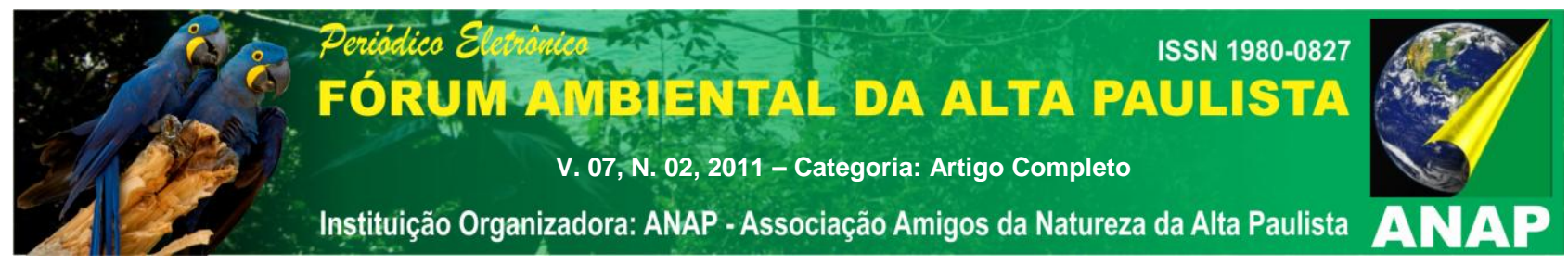

mananciais. Ou seja, recuperar este manancial tem também um sentido educativo e de mudança cultural.

Da mesma forma que a questão de abastecimento urbano, a utilização racional dos recursos naturais faz-se urgente nas zonas rurais frente ao desgaste $e$ empobrecimento dos solos e assoreamento de corpos d'água, os quais contribuem para a diminuição da renda e da qualidade de vida dos produtores rurais e de suas famílias. Esses problemas são freqüentes na região oeste do Estado de São Paulo, exigindo providências dos órgãos públicos e o manejo adequado de solos e água por parte dos produtores rurais, visando sua conservação. Para isso, é indispensável a adoção de algumas práticas que controlem o escoamento superficial de água, favoreçam a cobertura vegetal e facilitem a infiltração de água no solo.

Tais práticas são essenciais na zona rural do município de Regente Feijó, por apresentar problemas generalizados de erosão e assoreamento de cursos d'água (GOLLA, 2006).

Um dos importantes afluentes do manancial Rio Santo Anastácio é o Córrego do Embiri (Figura 2). 

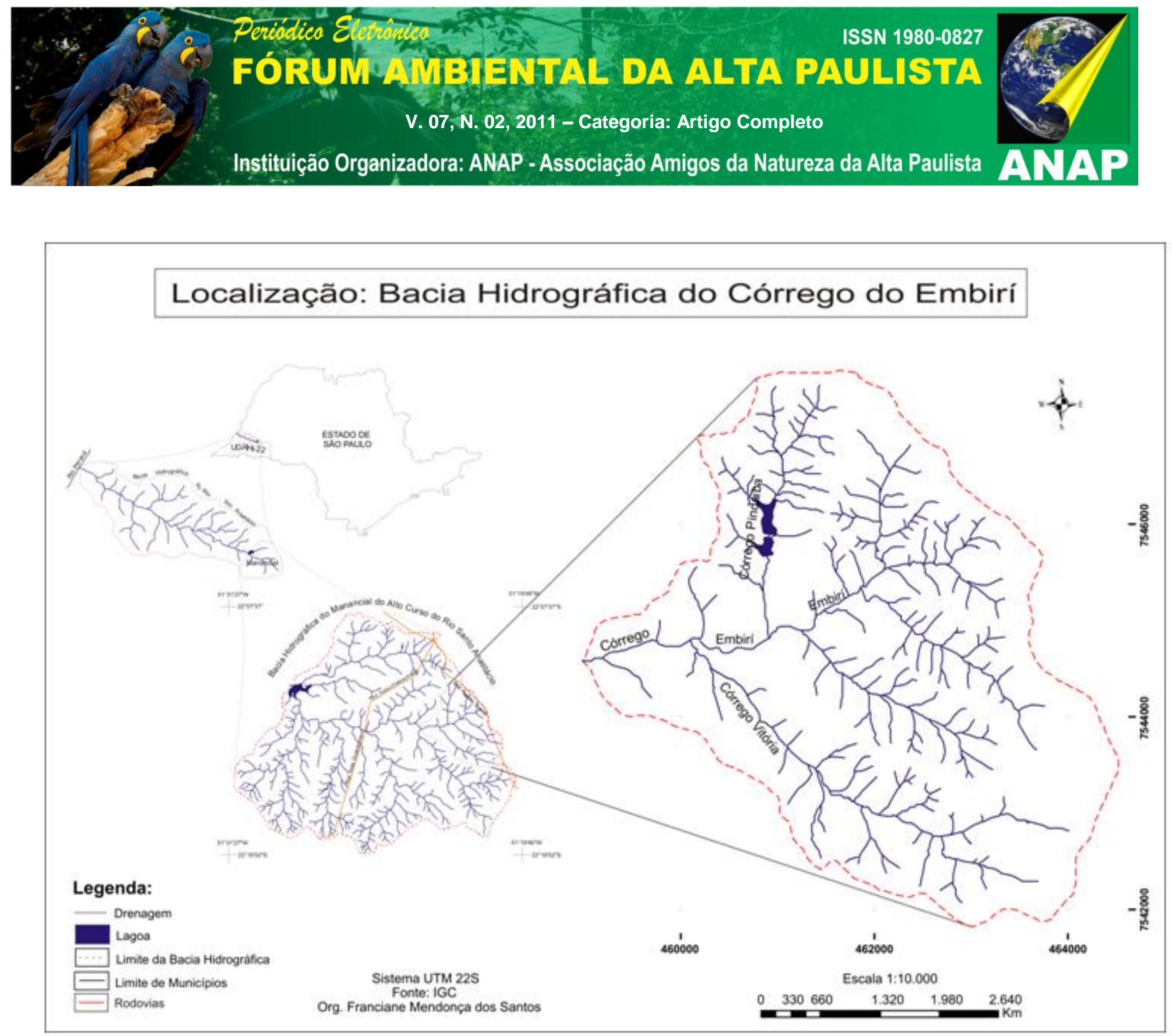

Figura 1 - Mapa de localização da Bacia Hidrográfica do Córrego do Embirí

O Córrego do Embiri possui área de aproximadamente 19,16 km² e perímetro da bacia hidrográfica de $19,30 \mathrm{~km}$, nasce a uma altitude aproximada de 480 metros, seguindo no sentido NE-W. Os afluentes da margem esquerda do Córrego do Embiri nascem a uma altitude média de 480 metros. A bacia do Embiri possui 1,48 segmentos de canais fluviais por $\mathrm{km}^{2}$ (densidade hidrográfica) e $1,66 \mathrm{Km}$ de canais por $\mathrm{Km}^{2}$ (densidade de drenagem).

De acordo com Dibieso (2007), as pastagens constituem-se na categoria de uso do solo predominantemente na bacia; outra característica é a área urbana localizada nas nascentes do Córrego do Embirí e o trecho expressivo de vegetação nativa localizado no setor NW da Bacia.

A nascente do Córrego do Embirí encontra-se no município de Regente Feijó e sua foz no Rio Santo Anastácio localiza-se no município de Presidente Prudente - SP. Na parcela da bacia localizada em Presidente Prudente, encontra-se o parque ecológico Cidade da Criança, um dos locais mais visitados no município. Este parque ecológico 


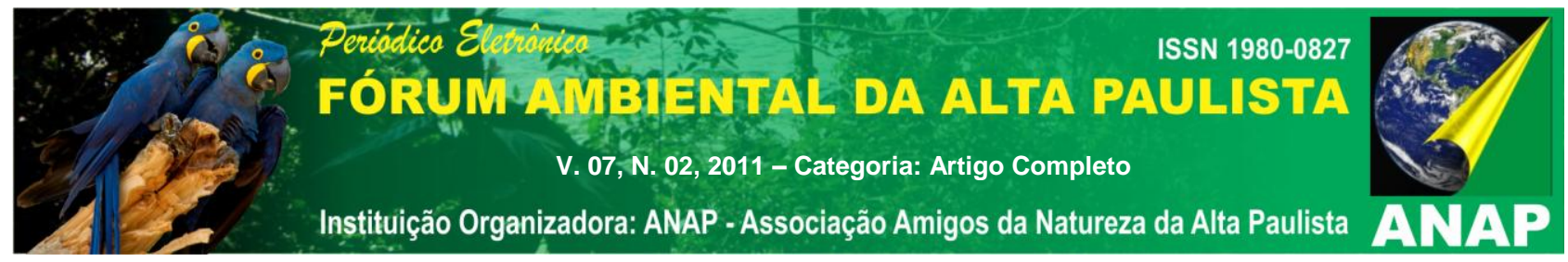

compreende uma área de aproximadamente 72 alqueires, constituindo um complexo paisagístico formado por matas, bosques, lagos, pequeno zoológico, estradas asfaltadas, quiosques, quadra de basquete e futebol, teleférico, centro administrativo, centro educacional e de apoio a projetos sociais, dentre outros.

Em Regente Feijó, foram realizadas diversas iniciativas com intuito de recuperar a qualidade ambiental da área dessa bacia em função de seus diversos problemas ambientais, como exemplo pode-se citar o Projeto de Recuperação da Nascente do Córrego do Embirí, que visa aumentar o volume de água e aumentar a preservação ambiental ao redor deste curso d'água.

Nesse sentido, essa pesquisa visa contribuir com os estudos e ações em prol deste córrego, na perspectiva maior de recuperação e proteção do manancial.

\section{4 - PROCEDIMENTOS METODOLÓGICOS}

O mapa ambiental participativo foi elaborado a partir da reunião de mapeamento participativo com as comunidades do bairro do Palmitalzinho, onde surge um afluente de suma importância para o Rio Santo Anastácio, denominado Córrego do Palmitalzinho. Foi complementado com trabalhos de campo na Bacia Hidrográfica do Córrego do Embirí, para observação da área de pesquisa e diagnóstico de possíveis riscos ambientais, juntamente com a equipe colaboradora da pesquisa de pós-doutorado do Dr. Salvador Carpi Jr. cujos estudos sobre mapeamento dos riscos ambientais na Alta Bacia do Rio Santo Anastácio, incluem a bacia hidrográfica do Córrego do Embirí.

Ainda quanto ao estudo supracitado houveram inúmeras atividades inclusive atividades externas. Tais como: a elaboração e entrega de cartazes pelas áreas de abrangência da pesquisa para a divulgação das atividades de mapeamento participativo nas propriedades rurais dos bairros e também nas igrejas, além das atividades de mapeamento participativo propriamente dito.

Durante esses encontros ocorriam breves explicações sobre o intuito da pesquisa, em seguida reuníamos os integrantes em grupos, cada um com um mapa base da área. Cada grupo era orientado por um membro da equipe, e assim ocorriam os apontamentos de riscos. Por fim, reuníamos novamente todos e fazíamos um debate final sobre os riscos apontados e considerações finais. 


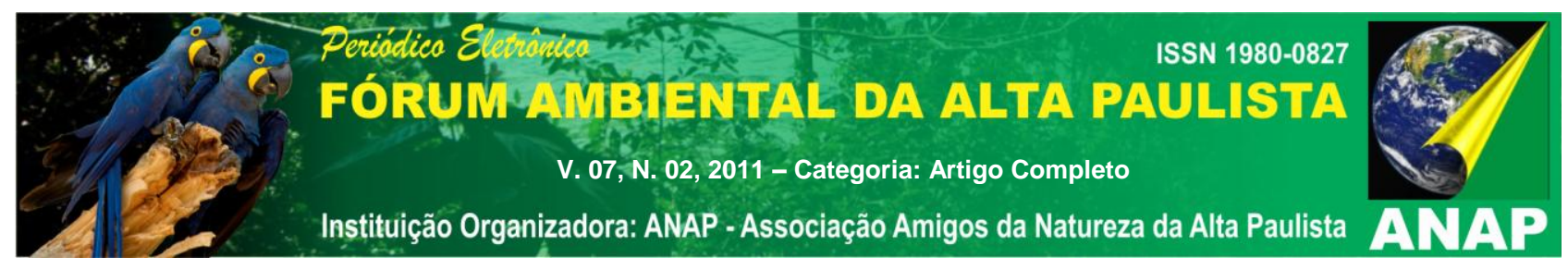

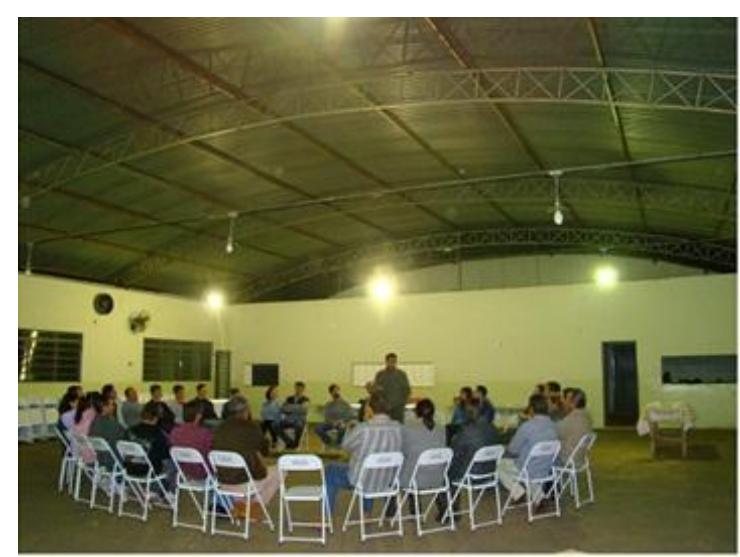

Foto 1

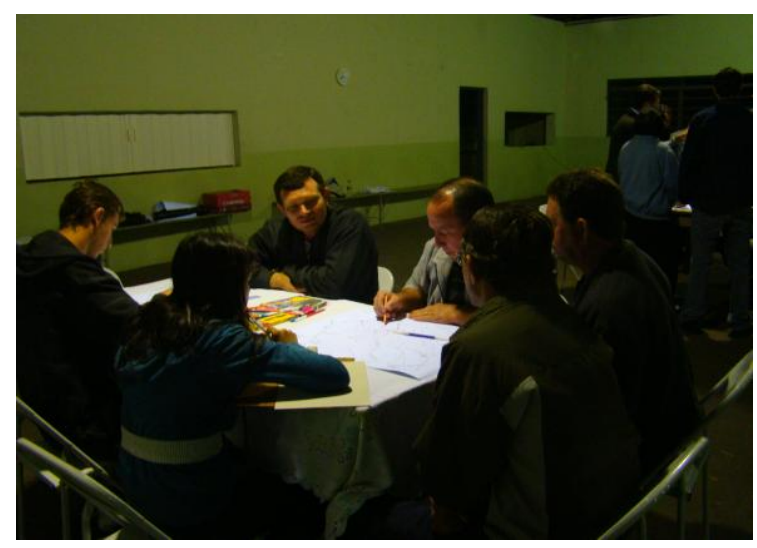

Foto 3

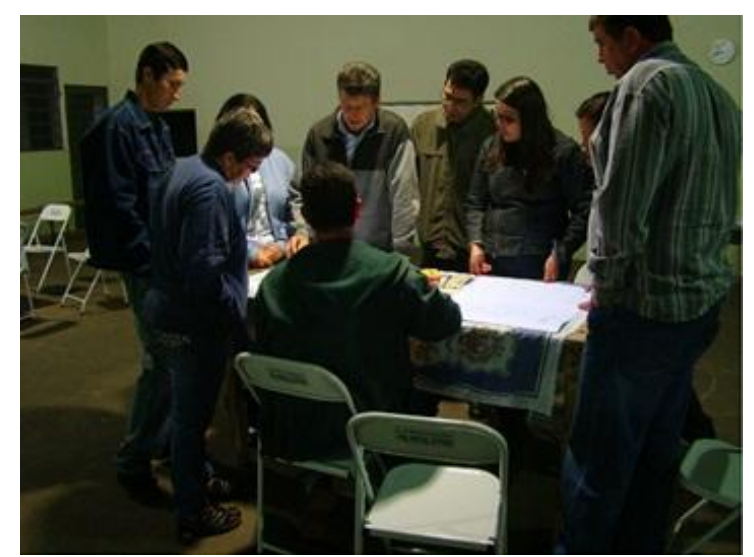

Foto 2

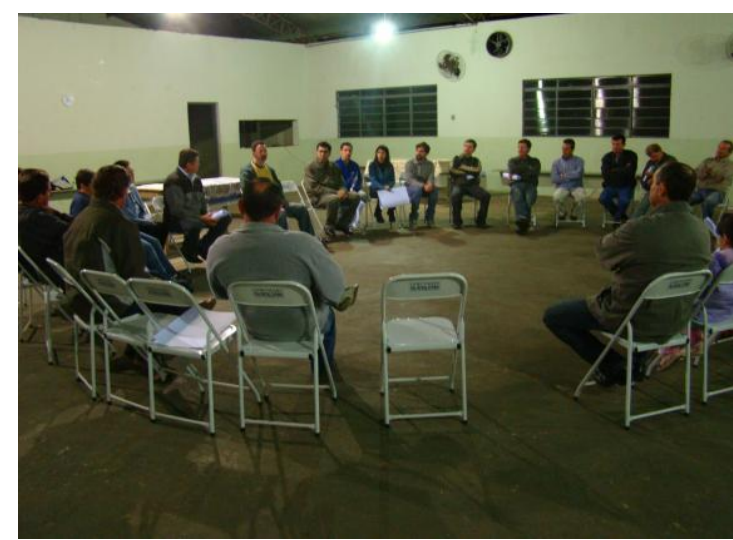

Foto 4

Foto 1: reunião pública de mapeamento ambiental participativo no bairro Palmitalzinho, com esclarecimentos iniciais; Fotos 2 e 3: divisão em grupos e; Foto 4: debate final. Fonte: OLIVEIRA (2010)

Após a reunião, com intuito de obter mais informações sobre a área obtivemos a colaboração de alguns profissionais bastante conhecedores de toda a bacia do Rio Santo Anastácio, ligados ao Comitê da Bacia do Pontal do Paranapanema, Companhia de Desenvolvimento Agrícola de São Paulo (CODASP) e Marcos Norberto Boin, do Ministério Público do Estado de São Paulo. Em reuniões tais colaboradores efetuaram 


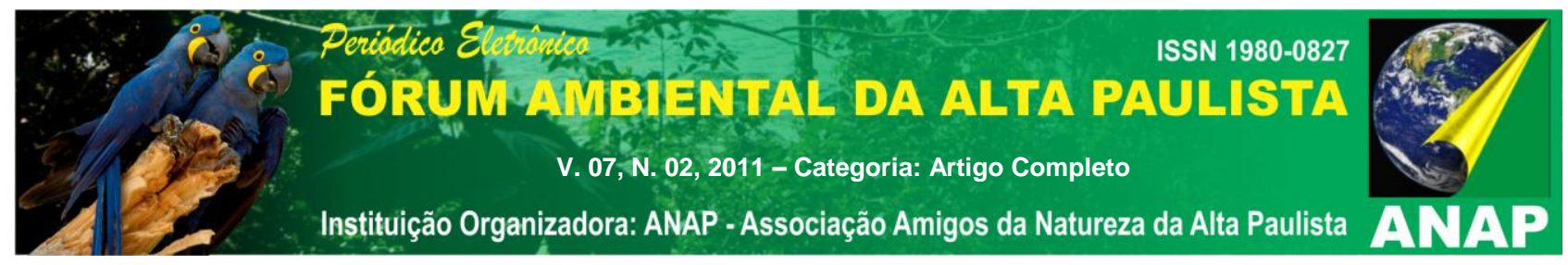

alguns relatos e indicaram no mapa alguns aspectos de interesse para esta pesquisa, propiciando uma abrangência um pouco maior do mapeamento.

Por fim podemos considerar que através das atividades desenvolvidas e descritas acima foi possível conhecer melhor a área da bacia hidrográfica do Córrego do Embirí, e destacar algumas características da realidade local que incluem problemas ambientais, e necessidades das comunidades, através da elaboração do mapa ambiental participativo.

Sua elaboração foi feita através do mapa base da bacia hidrográfica do córrego do Embirí e com a indicação dos riscos ambientais através da manipulação do Software CorelDraw X4.

\section{5 - ANÁLISE DOS RESULTADOS}

O mapa de riscos ambientais, chamado de mapa ambiental participativo em razão das indicações serem de caráter exclusivo da população que vive na bacia hidrográfica e que convive com esses riscos, representa os riscos ambientais indicados pela participação pública e trabalhos de campo para complementação e verificação dessas informações. Com isso pode-se sistematizar as informações adquiridas e elaborar um mapa ambiental participativo da bacia hidrográfica do córrego do Embiri (Figura 2). 

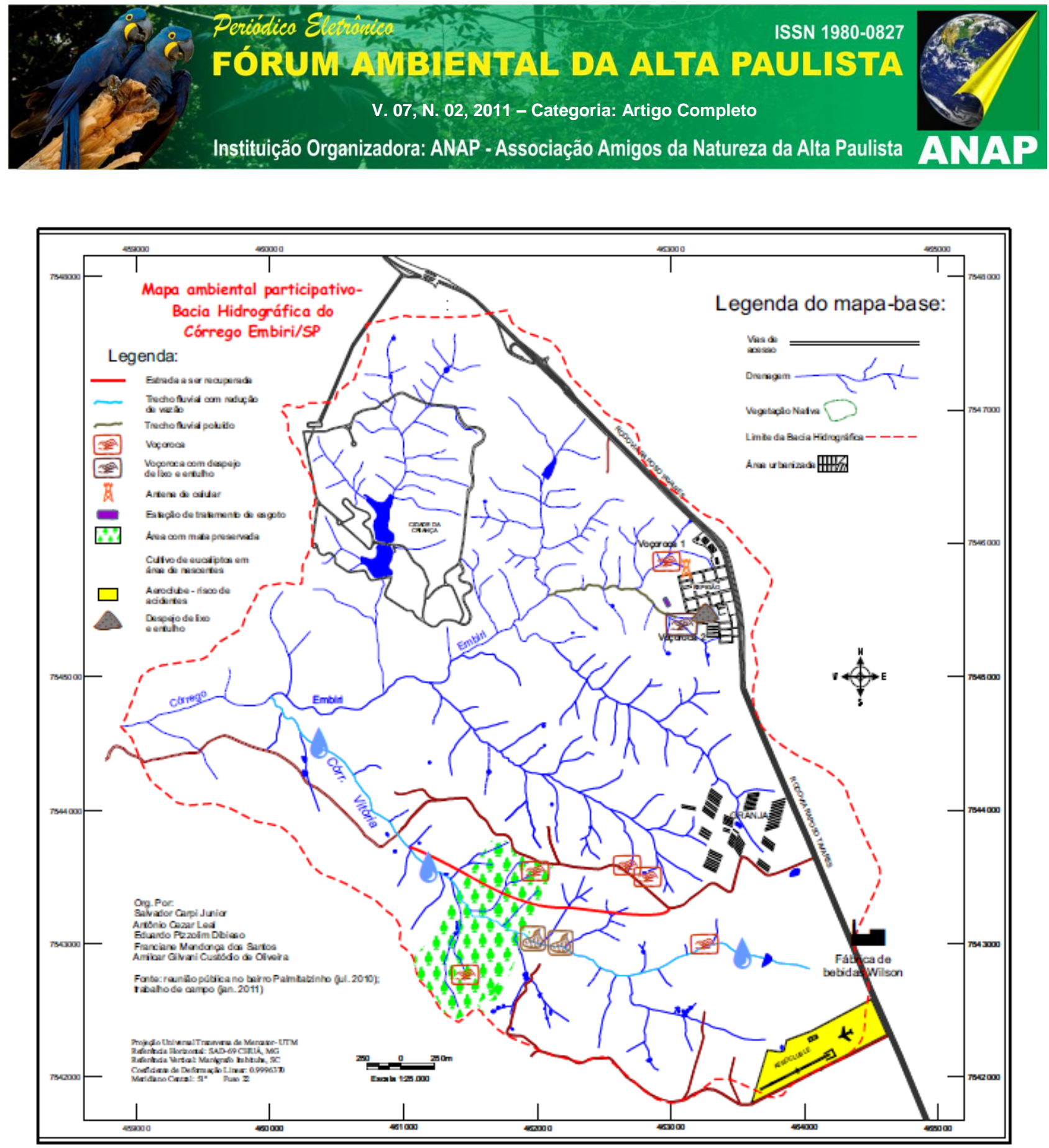

Figura 2 - Mapa ambiental participativo da Bacia Hidrográfica do Córrego do Embirí

No mapa ambiental participativo final, observa-se que a área de pesquisa encontra-se em degradação substancial, necessitando de intervenções para estabelecer sua recuperação. Pode-se observar, durante o trabalho de campo, principalmente a presença de diversas voçorocas (foto 5 ) distribuídas pela bacia utilizadas pela população muitas vezes para despejo de lixo e entulhos (foto 6). 

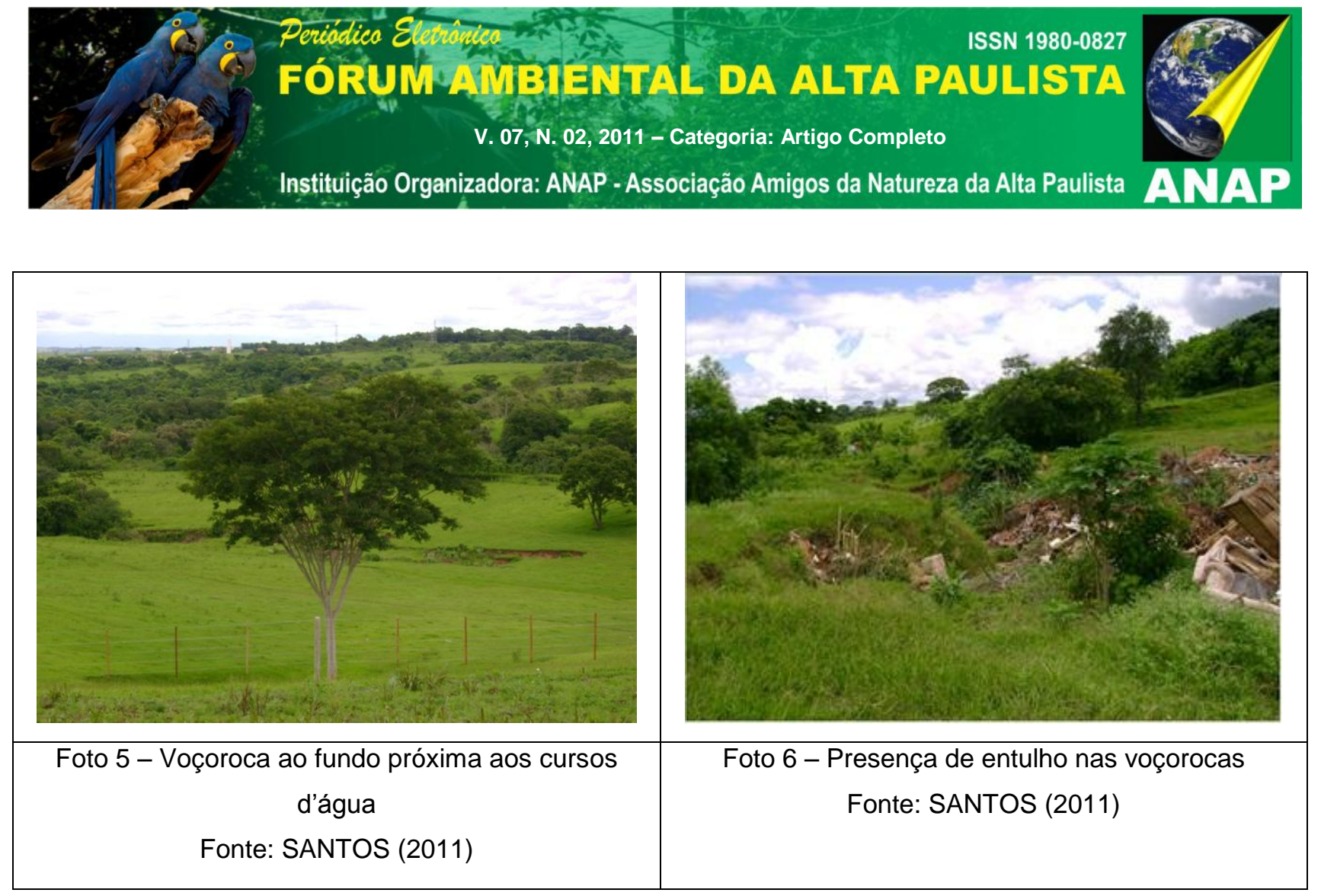

Essas voçorocas são decorrentes do forte processo erosivo originado do escoamento de águas pluviais para o fundo de vale, com as vertentes sem proteção. Esta situação perturba a condição de equilíbrio natural da camada superficial do solo, criando sérios problemas para o desenvolvimento da agricultura nos arredores e também para o manejo dos recursos hídricos da área urbana local. A água (das chuvas ou da drenagem urbana) é o principal agente erosivo, além da influência da topografia do terreno, do tipo de solo, da cobertura vegetal e do clima que serão estudadas posteriormente neste trabalho.

Nota-se também um trecho fluvial poluído pelo despejo de resíduos nas voçorocas que seguem para o curso d'água, ocorrendo contaminação. Além disso, em razão da grande quantidade de sedimentos lançados no curso d'água ocorre a redução de vazão de um trecho fluvial em períodos do ano. Observa-se um trecho de estradas a serem recuperadas, e a presença da antena de celular no distrito do espigão localizado no município de Regente Feijó, próxima a residências, capaz de oferecer riscos a saúde da população devido a radiação eletromagnética emitida quando operam.

De acordo com Dias \& Siqueira (2002) não é possível afirmar que a exposição à irradiação de microondas seja totalmente livre de causar potenciais efeitos adversos à saúde, mesmo porque os estudos do potencial cancerígeno ainda não são concretos, e sendo assim deve-se incentivar pesquisas nesse sentido que já vem sendo amplamente desenvolvidas. A princípio deve-se realizar a precaução e atender a legislação que diz 


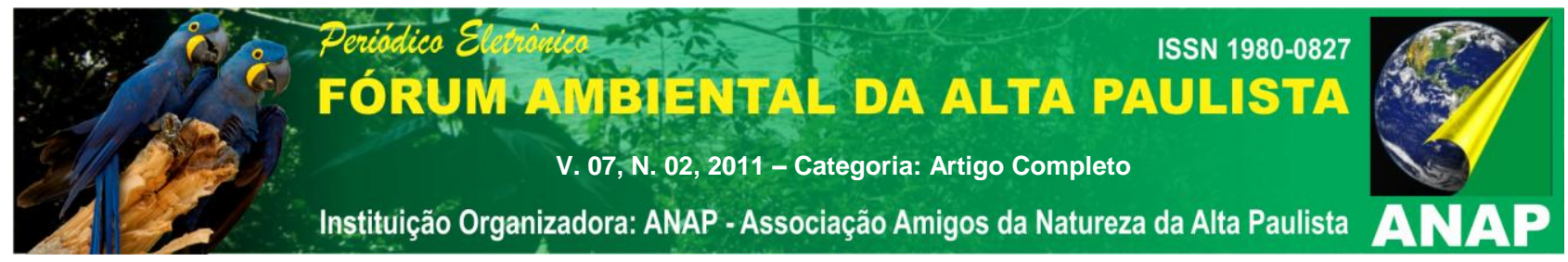

respeito à implantação de antenas de celular com segurança. Em São Paulo, a comprovação de atendimento dos limites estabelecidos pela Resolução da ANATEL por meio de laudo técnico; proibição de instalação em: presídios, cadeias e FEBEM, hospitais e postos de saúde; escolas, asilos e casas de repouso; postos de combustíveis; distância mínima entre antenas de cem metros; estabelecimento de recuos; montagem de sistema de informação sobre localização e funcionamento de ERBs; fiscalização pelas Subprefeituras.

Próximo ao distrito do Espigão localiza-se a estação de tratamento de esgotos que pode ser um risco ambiental em caso de vazamento, tal como o aeroclube em caso de acidentes, como indicado pelos moradores. O cultivo de eucaliptos (vegetação não nativa) nas áreas de nascentes também se caracteriza como riscos ambientais devido a este tipo de vegetação esgotar a fertilidade do terreno, e gerar poucos nutrientes podendo causar erosões ou a compactação do solo. No entanto, os riscos ambientais apontados pelos moradores relacionam também aspectos positivos em relação ao meio ambiente como o caso da área com mata preservada representada no mapa.

\section{6 - CONSIDERAÇÕES FINAIS}

As atividades realizadas com a comunidade rural propiciaram o mapeamento participativo de riscos ambientais na bacia do córrego do Embirí e foi possível perceber que a área sofre diversos problemas ambientais. Através da visão in loco das condições da área de pesquisa no que tange a ação antrópica pode-se comprovar que a área encontra-se em degradação substancial que pode comprometer o sistema hídrico da região. Como resultado importante, destaca-se a elaboração do mapa ambiental participativo da Bacia Hidrográfica do Córrego do Embirí, que será utilizada na pesquisa sobre planejamento ambiental desta bacia hidrográfica.

Desta forma, as atividades realizadas geraram uma base de dados ampla sobre os riscos ambientais apontados pela população e que quando compiladas, poderão fornecer subsídios para o planejamento ambiental da área, mediante propostas e recomendações, integrando a pesquisa com as necessidades das administrações municipais, estadual e federal. 


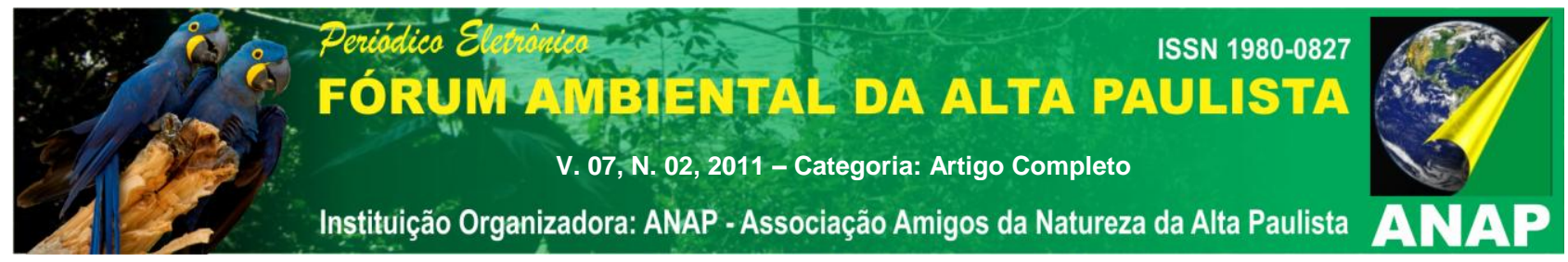

Assim, além do levantamento dos problemas que afetam o ambiente local, este método também pode ser utilizado para a elaboração de propostas e recomendações para evitar as situações constatadas e orientar ações de recuperação ambiental. Ao se integrar às necessidades do poder público, revela-se importante instrumento de planejamento de bacias hidrográficas, enquanto que os participantes adquirem um ganho inestimável em termos de aprendizado, troca de experiências e incentivo às suas atividades como profissionais e cidadãos atuantes na área.

AGRADECIMENTOS: A Universidade Estadual "Júlio de Mesquita Filho", Faculdade de Ciência e Tecnologia, Campus de Presidente Prudente pela possibilidade de formação, a FAPESP/CNPQ pelo aporte financeiro, e a Carina Regina Macedo pelo apoio prestado.

\section{BIBLIOGRAFIA}

ACSELRAD, Henri; COLI, Luis Régis. (2008) Disputas territoriais e disputas cartográficas. In.: ACSELRAD, Henri. (Org.) Cartografias sociais e território. Instituto de Pesquisa e Planejamento Urbano e Regional , Universidade Federal do Rio de Janeiro Rio de Janeiro - RJ 168 p. (Coleção Território, Ambiente e Conflitos sociais; n. 1). p. 13 - 43

ALMEIDA, J.R. et al.(1993) Planejamento Ambiental. Ed.:Biblioteca Estácio de Sá. Rio de Janeiro - RJ. 153p.

CARPI JR, Salvador. (2001). Processos erosivos, riscos ambientais e recursos hídricos na Bacia do Rio Mogi-Guaçu. Tese de Doutorado em Geociências e Meio Ambiente. IGCE/UNESP, Rio claro - SP. 188 p. Orientação: Prof. Archimedes Perez Filho. Disponível em www.nepam.unicamp.br/downloads/tese final salvador.pdf.

CTPI - COOPERATIVA DE SERVIÇOS, PESQUISAS TECNOLÓGICAS E INDUSTRIAIS. (1999). Diagnóstico da situação dos recursos hídricos da UGRHI - 22. Pontal do Paranapanema: Relatório Zero. CPTI. CD-ROM São Paulo - SP

DAGNINO, Ricardo de Sampaio; CARPI JUNIOR, Salvador. Risco ambiental: conceitos e aplicações. CLIMEP - Climatologia e Estudos da Paisagem [Online] Rio Claro/SP, Brasil, 2:2, $\quad$ P. $50 \quad-\quad 87, \quad$ julho/dezembro $2007 . \quad$ Disponível: http://cecemca.rc.unesp.br/ojs/index.php/climatologia/article/view/1026/958. Acesso 20 de março de 2011. 


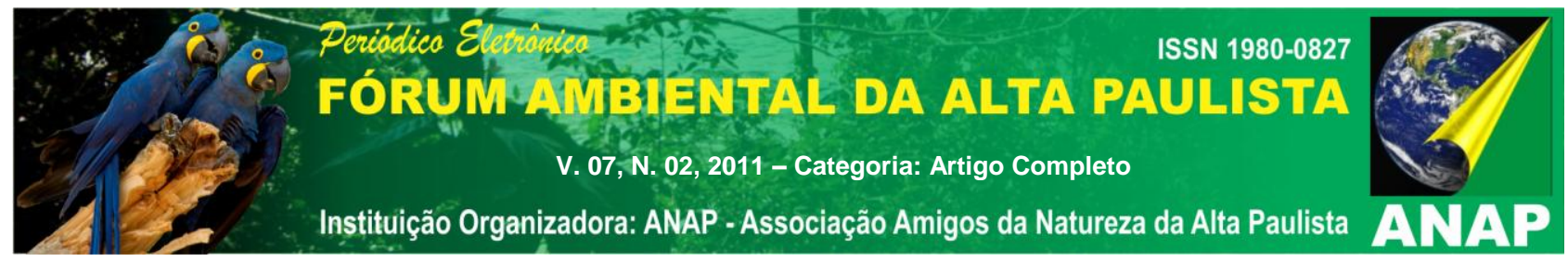

DIAS, M.,H., C.; SIQUEIRA, G., L. (2002) Considerações sobre os efeitos à saúde humana da irradiação emitida por antenas de estações Rádio base de sistemas de celulares, Revista científica periódica Telecomunicações Rio de Janeiro - RJ, v. 05, n. 1 .. DIBIESO, Eduardo Pizzolim. (2007) Planejamento Ambiental da Bacia Hidrográfica do Córrego do Cedro - Presidente Prudente/SP171f. Dissertação (mestrado) - Universidade Estadual Paulista, Faculdade de Ciências e Tecnologia Presidente Prudente - SP.

GOLLA, A. R. (2006) Meio Ambiente e Agricultura na Microbacia Hidrográfica do Córrego Palmitalzinho - Rejente Feijó/São Paulo. 90 f. Dissertação (mestrado) - Faculdade de Ciências e Tecnologia, Universidade Estadual Paulista Presidente Prudente - SP.

LEAL, A.C. (1995) Meio ambiente e urbanização na microbacia do Areia Branca Campinas - São Paulo. 155p. Dissertação (Mestrado em Geociências e Meio Ambiente) Instituto de Geociências e Ciências Exatas, Universidade Estadual Paulista Rio Claro SP.

MALJAZOVA, S.M., CJALOV, R.S. (2004) Los procesos antropógeno - naturales y los riesgos ecológicos., Tomo IV., Facultad de Geografía, Universidad Estatal de Moscú Editorial Gorodets, Moscú - RU.

MOTA, S. (1995) Preservação e conservação de recursos hídricos. 2.ed. ABES Rio de Janeiro - RJ.

OLIVEIRA, D.F. (2010). Coletânea de fotos. Gadis - Grupo de Pesquisa Gestão Ambiental e Dinâmica Socioespacial Presidente Prudente - SP.

REBELO, Fernando. Riscos naturais e ação antrópica: estudos reflexões. (2003) 2a Ed. revista e aumentada. Imprensa da Universidade Coimbra - PT. 286p.

SÁNCHEZ, L.E. (2008) Avaliação do impacto ambiental. 1.ed. Editora Oficina de textos São Paulo - SP.

SANTOS, F.M. (2011). Coletânea de fotos. Gadis - Grupo de Pesquisa Gestão Ambiental e Dinâmica Socioespacial Presidente Prudente - SP.

SANTOS, R.F. dos. (2004) Planejamento Ambiental: teoria e prática. Oficina de textos São Paulo - SP.

SEVÁ Fo, A. Oswaldo. (Org.), (1997). Riscos técnicos coletivos ambientais na Região de Campinas. NEPAM-UNICAMP, Campinas - SP. 70 p. Disponível em www.fem.unicamp.br/ seva. 
SILVA, V.S.; RODRIGUEZ, J.M.M.; MEIRELES, J.A.M. (2011). Planejamento ambiental e bacias hidrográficas (tomo 1). 1. Edições UFC Fortaleza - CE.

VEYRET, Yvette (Org.), (2007). Os Riscos - o Homem como agressor e vítima do meio ambiente. Contexto São Paulo - SP. 320p.

VEYRET, Yvette \& MESCHINET DE RICHEMOND, Nancy. (2007). O Risco, os riscos. In: VEYRET, Yvette (Org.) Os Riscos - o Homem como agressor e vítima do meio ambiente. Contexto São Paulo - SP. p. 23-79. 